Aleksej Kišjuhas

Univerzitet u Novom Sadu

Filozofski fakultet

Odsek za sociologiju

aleksej.kisjuhas@ff.uns.ac.rs

UDK 323.15:316.72

\title{
MANJINSKI IDENTITETI: PERSPEKTIVA TEORIJE KONTROLE AFEKTA I TEORIJE KONTROLE IDENTITETA
}

Apstrakt: U radu su predstavljeni i analizirani manjinski identiteti iz perspektive teorija kontrole afekta i kontrole identiteta. U pitanju su savremene sociološke teorije društvene interakcije i društvenih emocija, a koje ilustrativno referišu ka fenomenu društvenog identiteta individue. Analizirano je na koji način mehanizmi kontrole afekta i kontrole identiteta, odnosno društvene emocije i društveno značenje u kontekstu društvene interakcije i društvene strukture, utiču na generisanje i potvrđivanje (manjinskih) identiteta. Na ovaj način, teorije kontrole afekta i kontrole identiteta predstavljene su kao teorijski okvir ili objašnjenja društvenog ponašanja sa značajnim posledicama po fenomen (is)trajnosti i politike očuvanja manjinskih identiteta.

Ključne reči: Identitet, manjinski identiteti, teorija kontrole afekta, teorija kontrole identiteta, značenje, društvene emocije.

Termin "identitet" bio je gotovo nepoznat u sociologiji i društvenim naukama u periodu pre Drugog svetskog rata. S druge strane, fenomen identiteta u drugoj polovini 20. veka postaje predmet značajne teorijske i istraživačke pažnje (Coupland, 2007). Rodni i etnički identiteti su danas u prvom planu interesovanja sociologije, dok je pre nekoliko decenija to bio klasni identitet, obično obuhvaćen pojmom i analizom klasne svesti (vidi Aronowitz, 1992). Moguće je govoriti i o ekploziji identiteta u savremenom društvu, zbog čega baratanje ili upravljanje identitetom postaje fenomen od izuzetnog socijalnog značaja (Pullen, 2006). Dakle, identitet je istovremeno i "ključna reč" savremenog društva, centralni fokus teorije i istraživanja socijalne psihologije (Howard, 2000), ali i tema interesovanja savremene filozofije (vidi npr. Martin and Barresi, 2003).

U tom smislu, predmet značajnog teorijskog, ali i praktičnog interesovanja postaju i tzv. manjinski identiteti, uključujući tu i manjinske etničke, verske, rasne, seksualne itd. identitete u multikulturnim društvima. Istovremeno, manjinski identitet je tipična relaciona $\mathrm{i} / \mathrm{ili}$ relativna kategorija, pošto manjinski identiteti $u$ 
nekom društvu (kulturi) mogu biti ili jesu većinski identiteti u nekom drugom društvu, odnosno kulturi (etničkih Hrvata u Srbiji ili etničkih Srba u Hrvatskoj, na primer). Ipak, činjenica je da manjinski identiteti predstavljaju poseban teorijski izazov u smislu njihove relativne trajnosti, salijentnosti (istaknutosti), potvrđivanja, ali i gubitka i nestanka pred procesima akulturacije, asimilacije itd. Iz tih razloga, oni su i predmet mnogih političkih i društvenih intervencija, odnosno javnih politika.

Činjenica je i da se identitet (a posebno etnički i verski identitet) neretko definiše u okvirima nacionalističkih narativa $\mathrm{i} / \mathrm{ili}$ narativa o nacionalizmu (većinske i/ili manjinske zajednice). Naime, tradicionalna ideja o naciji u kontekstu ideologije nacionalizma je zamisao o ljudima koji su tokom istorije imali zajedničko poreklo i kulturu, kao i zajedničku fizičku teritoriju, politički sistem ili državu, religiju, običaje, jezike, mitove itd. (Škorić i Kišjuhas, 2015). S druge strane, mnogi manjinski (etnički) identiteti - kao npr. u slučaju Rusina - ne impliciraju postojanje zajedničke države u istoriji. Zatim, mnogi autori svedoče da su nacije kao "izmišljene zajednice" plod intelektualne imaginacije, pri čemu percepcija igra važnu ulogu u povezivanju ljudi u entitet poput nacije, odnosno u grupu sa zajedničkim identitetom (Anderson, 1983/1991). Za Andersona, nacija je socijalna konstrukcija u kojoj ljudi imaju "izmišljeno" verovanje ili osećanje da pripadaju istom entitetu, zato što neguju određeni kolektivni ili društveni identitet, neretko putem verovanja u zajedničku istoriju, odnosno kulturno nasleđe. $U$ tom smislu, inspirativne su i ideje o "izmišljanju tradicije" koje dodatno osnažuju osećanja pripadnosti naciji, odnosno verovanjima u objektivnost nacije, njene istorije i identiteta (Hobsbawm and Ranger, 1983).

Tipična sociološka konceptualizacija identiteta obično polazi od pretpostavke da je svaki ljudski identitet istovremeno i socijalni ili društveni identitet (Jenkins 2004: 4). Tvrdi se da proces identifikacije sebe ili drugih čini proces koji nužno inkorporira značenje koje se stiče u društvenoj interakciji, odnosno u izgradnji sopstva (vidi i Kashima, Foddy and Platow, 2002). U pitanju je proces koji je karakteristično dinamičkog karaktera, tj. on nije nešto što prosto "postoji”, već se mora uspostaviti putem procesa klasifikacije, asocijacije itd. S tim u vezi, identitet često podrazumeva dva kriterijuma komparacije između osoba ili stvari: sličnost i razliku. Sociolozi karakteristično tvrde da se identitet formira na distinktivno socijalan način, putem društvene interakcije, institucionalne prinude i tome slično. Dakle, identitet pojedinca nije fiksiran, već se menja tokom vremena i društvenog iskustva (reputacije se menjaju, a neki identiteti poput sveca ili mučenika se dobijaju nakon smrti itd.).

Najzad, poseban teorijski izazov u vezi sa (re)definisanjem identiteta predstavlja i analiza značenja manjinskog identiteta u okvirima određene dominantne (većinske) kulture, ali i analiza društvenih emocija u vezi sa (manjinskim) 
identitetima. Tada posebno istaknuto mesto igraju teorija kontrole afekta i teorija kontrole identiteta kao savremene i sofisticirane teorije društvene interakcije i društvenih emocija. U pitanju su i teorije koje na podsticajan način problematizuju i konceptualizuju fenomen identiteta, zbog čega je o njima inspirativno razmišljati i u kontekstu manjinskih identiteta. Drugim rečima, postavlja se pitanje šta tačno znači biti crnac, katolik, Rusin ili homoseksualac u društvu u kojem većinu čine belci, pravoslavci, Srbi ili heteroseksualci, odnosno kakve društvene emocije i identitete generišu ta socijalna značenja. Na sva ova pitanja nastoje da odgovore teorije koje su predmet ovog rada.

\section{TEORIJA KONTROLE AFEKTA}

Osnovna pretpostavka teorije kontrole afekta Dejvida Hajsea jeste da se individue u nekom društvu pre svega ponašaju na način putem kojeg mogu da održe svoj osnovni identitet (Heise, 1977; 1979; 2007; Smith-Lovin and Heise, 1988). Naravno, ovo može biti i manjinski identitet u okvirima društva sa nekom drugom (većinskom) kulturom. Zatim, ova teorija tvrdi i sledeće: ukoliko se dogodi nešto što dovodi u pitanje validnost tog identiteta (akcija koju sami iniciramo ili koju čine drugi), pojavljuju se određene emocije (Kemper, 2000: 780; vidi i Robinson, Smith-Lovin and Wisecup, 2006). Drugim rečima, teorija u vezu dovodi održanje identiteta i (pozitivne i negativne) emocije, odnosno afekte.

Da bi se u kontekstu manjinskih identiteta adekvatno predstavila i analizirala teorija kontrole afekta, neophodno je ukratko predstaviti teoriju i metodu semantičkog diferencijala koja je otvorila mogućnost za adekvatnu kvantifikaciju kvalitativnih sadržaja (Osgood, Suci and Tannenbaum, 1957). Naime, Hajse je bio student Čarlsa Ozguda, tvorca teorije o semantičkom diferencijalu, prema kojoj je moguće meriti afektivne asocijacije objekata, događaja i pojmova (tj. njihova konotativna značenja). S tim u vezi, semantički diferencijal predstavlja direktni ili eksplicitni metod merenja značenja objekata, događaja i koncepata. Analizom odnosa među skalama prideva, Ozgud i saradnici svojevremeno dolaze do tri primarne dimenzije značenja: evaluacije (E), potencije (P) i aktivnosti (A) (Osgood, Suci and Tannenbaum, 1957: 72-73).

Dimenzije evaluacije, potencije i aktivnosti (EPA) bile su od posebnog značaja za istraživanje emocija u okvirima Hajseove teorije kontrole afekta. On se prvobitno bavio dokazivanjem univerzalnosti i konzistentnosti EPA strukture, uključujući tu i istraživanje hiljadu najčešćih engleskih reči (Heise 1965), kao i istraživanje EPA strukture značenja među dve hiljade pojedinaca različitog socioekonomskog statusa (vidi Heise, 1970). Činjenica da ljudi poseduju zajednički 
okvir putem kojeg diferenciraju afektivna značenja koncepata upućuje na univerzalnost afektivnih struktura, što je i polazna osnova teorije kontrole afekta. ${ }^{1}$

Dakle, teorija kontrole afekta počiva na tri osnovne ideje: (1) pojedinci stvaraju događaje tako da potvrde osećanja koja imaju o sebi i drugima u datoj situaciji; (2) ukoliko događaji ne odgovaraju njihovim osećanjima, pojedinci će reidentifikovati sebe i druge; (3) u procesu izgradnje događaja radi potvrde osećanja, pojedinci izvode društvene uloge na osnovu kojih funkcioniše društvo (tzv. princip afektivne racionalnosti) (Heise, 1979). Drugim rečima, pojedinci se ponašaju tako da generišu osećanja koja su prikladna situaciji ili menjaju sopstvenu sliku o toj situaciji, dok emocije pojedinaca predstavljaju signale odnosa između individualnog iskustva i definicije situacije. Činjenica da se dimenzije evaluacije, potencije i aktivnosti mogu posmatrati kao kroskulturno univerzalne reakcije, Hajseu je poslužila kao efikasan način merenja simboličkog i emocionalnog značenja društvenih događaja i društvenih identiteta. Istovremeno, poseban izazov po teoriju kontrole afekta predstavljaju procesi potvrđivanja osećanja, reidentifikacije i izvođenja uloge u kontekstu manjinskih identiteta.

Prema Hajseu, pojedinci reaguju afektivno (ili na emocionalan način) na svaki društveni događaj, i to u skladu sa stepenom korespondencije između (1) uspostavljenih fundamentalnih afektivnih značenja i (2) prolaznih ili tranzientnih utisaka kao emocionalnih reakcija koje su specifične za datu situaciju (Heise, 1979: 14). Fundamentalni identitet označava afektivna značenja koja prevazilaze konkretne situacije, npr. identitet majke podrazumeva afektivna značenja "veoma dobra" (evaluacija), "delimično moćna" (potencija) i "delimično aktivna" (aktivnost). Na drugoj strani su prolazne situacije i osećanja koja one generišu, poput situacije majke koja grdi svoje dete, a koja su povezana sa značenjima da je majka, na primer, "delimično loša", "delimično nemoćna" i "veoma aktivna". S tim u vezi, na sličan način se (re)definišu i identiteti etničkih, rasnih ili verskih manjina, sa specifičnim "većinskim" definicijama u okvirima dominantne kulture. Fundamentalni identitet tada može biti proizvod dominantnih predrasuda i stereotipa o nekoj etničkoj zajednici, a tranzientni utisak može biti ponašanje pripadnika te etničke zajednice koje je suprotno stereotipu.

Proces kontrole afekta je moguće opisati na sledeći način: nakon razvijanja fundamentalnih i tranzientnih osećanja duž dimenzija evaluacije, potencije i aktivnosti, individue mobilišu svoju spoznaju i emocije u skladu sa sledećim karakteristikama svakog susreta: (1) sopstvom ili identitetom, (2) drugima i

1 Ove tvrdnje su bile predmet posebno detaljnih istraživanja u kontekstu američke i japanske ("zapadne" i "istočne") kulture, a koji su jasno ukazali na kulturnu univerzalnost semantičkih struktura u slučaju termina koji se odnose na emocije u engleskom i japanskom jeziku, uprkos prividnim razlikama (vidi Romney, Moore and Rusch, 1997; up. Rusch, 2004; za korejski jezik vidi Kim and Hupka, 2002). S druge strane, pojedina istraživanja koja koriste dimenzije evaluacije, potencije i aktivnosti ukazuju na razlike u značenju seksualno-erotskih emocija u američkoj i nemačkoj kulturi (vidi Schneider, 1993). 
njihovim identitetima, (3) ponašanjima sebe i drugih, (4) situacijom ili okruženjem u kojem se ponašanje odvija (Turner and Stets, 2005: 137). Važno je razumeti i da su osećanja kojima se Hajse bavi pre svega trans-situacione ili opšte afektivne reakcije na specifične simbole unutar jedne kulture.

Drugim rečima, u pitanju su trajni(ji) društveni konstrukti, u poređenju sa prolaznošću jednostavnih emocionalnih reakcija. U tom smislu, dimenzije evaluacije, potencije i aktivnosti su kulturno univerzalne, ali su pojedinačna osećanja proizvodi specifične kulture. Iako se pojedinačni koncepti (npr. oca ili majke, Srbina ili Rusina) međusobno razlikuju na individualnom planu, apstraktni koncept roditelja ili etničke grupe unutar jedne kulture ostaje relativno statičan. Kultura je ta koja determiniše značenja svakog aspekta susreta, što vodi u razvijanje osećanja o tome "koliko" evaluacije, potencije i aktivnosti "treba" da se dogodi, kao i "koliko" navedenih dimenzija se zaista događa. Na ovaj način, teorija kontrole afekta postaje prediktivna po karakteru. ${ }^{2}$

Istovremeno, Hajse je emocije posmatrao kao fenomene sa značenjima koji mogu otkriti dimenzije evaluacije, potencije i aktivnosti. U skladu sa tim je razvio i matematičke formule koje predviđaju različite individualne i društvene ishode, uključujući tu i osećanja, emocije i identitete (Heise, 2007). Naime, na osnovu EPA matrice, teorija kontrole afekta može da istraži kompleksne instance u kojima se javljaju različite emocije, uključujući tu i načine na koji drugi vide aktera i njegov identitet. Na primer, fundamentalno osećanje za identitet lekara obično je: dobar, snažan i rezervisan; za decu: dobra, slaba i glasna; za gangstere: loši, moćni i aktivni itd. (Heise, 2007: 7). Hajse je kasnije dodatno potvrdio univerzalnost semantičkih struktura u novim kroskulturnim istraživanjima univerzalnosti (dimenzija) značenja osećanja (Heise, 2010).

Dakle, suštinu teorije kontrole afekta čini objašnjenje kognitivnog i društvenog procesa u kojem pojedinci percipiraju, evaluiraju i kreiraju događaje oko sebe tako da bi održali određeni skup značenja. Ljudi se posmatraju kao bića koja razvijaju svest o svakoj pojedinačnoj situaciji, jezik je osnovno sredstvo za taj proces, dok afektivni procesi podstiču percepciju određene vrste i motivišu na akciju. U procesu definisanja situacije, pojedinci proizvode fundamentalna osećanja koje

2 Pošto se u ovoj teoriji emocije konceptualizuju kao oznake koje se dodeljuju našim osećanjima tokom ili nakon određenog događaja, postaje moguće razviti formalni, matematički model koji će predvideti koju emociju će pojedinac osećati nakon učešća u određenoj društvenoj interakciji (vidi i Averett and Heise 1987). Na primer, ukoliko muški predavač predstavi svoj identitet (profesor) u situaciji (učionica) pred drugima (studenti), ova činjenica sa sobom nosi određeni korpus kulturno definisanih nivoa evaluacije, potencije i aktivnosti. Međutim, ukoliko ova osoba počne da govori o npr. svom seksualnom životu, na delu je diskrepancija između fundamentalnih osećanja u vezi sa identitetom profesora i tranzientnih osećanja u vezi sa njegovim konkretnim ponašanjem. Proces kontrole afekta tada može imati nekoliko različitih scenarija: identitet profesora može ostati nenarušen, (npr. ukoliko se njegovo ponašanje interpretira kao da je u funkciji predavanja), može se dogoditi rekonceptualizacija situacije (npr. da predavanje još uvek nije počelo), a može se dogoditi i promena identiteta (npr. profesor se tada reinterpretira kao napasnik, osoba sa mentalnim poremećajem ili nešto slično) (Turner and Stets, 2005: 137-138). 
je moguće redukovati na tri dimenzije značenja (merljive spomenutom tehnikom semantičkog diferencijala). Navedena osećanja se zatim upoređuju i usklađuju sa trenutnim ili situacionim osećanjima, pri čemu motivacija za održanjem sklada između ovih osećanja proizvodi strukturne društvene pojave i fenomene poput identiteta, društvenih uloga i tome slično (Robinson, Smith-Lovin and Wisecup 2006). U pitanju je interpretativna sociologija društvene akcije koja polazi od analize značenja situacije i identiteta određenih pojedinaca ili društvenih položaja i uloga. S tim u vezi, pretpostavke i saznanja teorije kontrole afekta moguće je upotrebiti za mnogo šire teorijske poduhvate i objašnjenja čovekovog društvenog ponašanja i ljudske prirode.

Posebnu vrednost Hajseove teorije čini konceptualizacija samog procesa kontrole afekta kao mehanizma putem kojeg se (čak i manjinski) identiteti održavaju konzistentnim, uprkos dominantnoj kulturi ili procesima asimilacije, akulturacije itd. (vidi Heise, 1979: 29-31). Na ovaj način, Hajse dovodi emocije i identitet u direktnu ili neposrednu vezu, pri čemu kontrolu afekta vidi kao mehanizam koji je u samoj osnovi društvenog života. Kontrola afekta definiše se kao proces koji ima dramatične posledice po gotovo svaki aspekt svakodnevnog ponašanja, uključujući tu i relativnu trajnost manjinskih identiteta. $\mathrm{S}$ tim u vezi, mehanizam kontrole afekta je od velikog značaja kada je reč o politikama očuvanja manjinskih identiteta, jezika, kulture itd.

\section{TEORIJA KONTROLE IDENTITETA}

Na temelju Hajseovih ideja, razvijena je i slična ili konceptualno bliska teorija kontrole identiteta Pitera Berka i saradnika, a koja se dodatno usredsređuje na prirodu identiteta pojedinaca (Burke, 1980; 1991; 2004; 2007; Burke and Tully, 1977; Burke and Reitzes, 1981; Stets and Burke, 2000; 2003; Burke and Stets, 2009). To jest, u pitanju je teorija koja je fokusirana na odnos između identiteta pojedinaca, njihovih emocija i njihovog ponašanja, i to u kontekstu društvene strukture u kojoj su identiteti i ukorenjeni ili proizvedeni.

Uz nedvosmislenu inspiraciju Hajseovom teorijom kontrole afekta, Berkova teorija se nadovezuje i na Strajkerovu strukturalno interakcionističku teoriju identiteta (Stryker, 1980; vidi i Stryker and Burke, 2000; Stets, 2006a; 2006b). Središnju ideju ove teorije čini pretpostavka da je ponašanje utemeljeno na sociolingvistički imenovanom ili klasifikovanom svetu, odnosno da ljudi u društvu imenuju i klasifikuju sebe i jedni druge na osnovu položaja koje zauzimaju (Stryker, 1980: 53). Upravo ove oznake položaja, kao i očekivanja koja pojedinci imaju od navedenih položaja, tada postaju internalizovani kao identiteti koji čine sopstvo pojedinca (Stryker, 1980: 54). 
Iako se klasični interakcionistički teoretičari nisu ekplicitno bavili identitetom (već konceptom sopstva, npr. Mead, 1934; Blumer, 1969), njihove ideje su značajno oblikovale rad kasnijih interakcionista koji su izučavali identitete (vidi Stryker, 1980: 15-50). Sociolozi poput Strajkera i Berka su delimično prihvatili naglasak interakcionizma na konceptu značenja, kao i na emergenciji značenja iz društvene interakcije (vidi npr. Blumer, 1969: 2). Tvrdi se da čovekove akcije i interpretativne aktivnosti istovremeno $i$ konstituišu društvo $i$ determinisane su od strane društva. $\mathrm{Na}$ osnovu toga se i (manjinski) identiteti posmatraju kao fenomeni koji su društveno determinisani, ali i koji su aktivno (re-)kreirani od strane individua.

S druge strane, Strajkerova "strukturalna" verzija simboličkog interakcionizma nedvosmisleno ističe da je društvena struktura ta koja utiče na sopstvo, identitet, definicije situacije, društveno ponašanje i drugo, pre svega zato što se u okvirima društvene strukture nalaze resursi koji društvenu interakciju čine mogućom (Stryker, 1980: 52). Dakle, iako se navodi da je ličnost oblikovana društvenim interakcijama, tvrdi se da je društvena struktura ta koja oblikuje mogućnosti za interakciju. Iz tih razloga, teorijsko usredsređivanje samo na ličnost ili samo na strukturu nužno ostaje "parcijalno i nedovršeno" (Stryker, 1980: 53). Zato je pre detaljnije analize Berkove teorije kontrole identiteta, neophodno predstaviti i Strajkerovu interakcionističku teoriju identiteta. Obe teorije dele pretpostavke o tome da osobe prvenstveno delaju u okvirima društvene strukture, kao i da tokom društvene interakcije nameravaju da zadrže određeni identitet, u meri u kojoj je to moguće (Turner, and Stets 2005: 124).

Kada je reč o identitetu, Strajker se posebno usredsredio na fenomen istaknutosti (ili salijentnosti) identiteta, zbog čega je posebno inspirativno razmisliti o relativnoj istaknutosti manjinskih identiteta. Posvetio se i detaljnoj analizi posledica koje identitet ima po izvođenje društvene uloge, kao i na fenomen (promenljivih) posvećenosti individua konkretnom identitetu (Stryker, 1980: 60-61). On je identitet analizirao u kontekstu ponašanja orijentisanog ka odabiru i izvođenju uloge, postavljajući pitanja o tome zašto (kada je izbor moguć) ljudi odabiraju jedno ponašanje orijentisano ka ulogama umesto nekog drugog. To jest, zašto ljudi posvete veliki deo svog vremena i truda samo jednoj oblasti svog života (npr. porodici ili poslu), koje su posledice odabira uloge po tekuću interakciju i društvene odnose itd. Da bi odgovorio na ova pitanja, Strajker ističe niz ilustrativnih hipoteza kojima pokušava da predstavi teoriju o međuodnosu sopstva i društva pri determinisanju identiteta. ${ }^{3}$

3 Ove hipoteze glase: (1) što je veća posvećenost nekom identitetu, taj identitet će biti istaknutiji; (2) što je veća posvećenost nekom identitetu i pozitivnija je evaluacija tog identiteta, taj identitet će biti istaknutiji; (3) što je više neka posvećenost identitetu zasnovana kao suprotstavljena drugim identitetima koji mogu ući u mrežu posvećenosti, taj identitet će biti istaknutiji; (4) što se više podudaraju očekivanja uloga onih koji su posvećeni nekom identitetu, taj identitet će biti istaknutiji; (5) što je veći broj osoba uključenih u mrežu posvećenosti nekom identitetu, taj identitet će biti istaknutiji; (6) što je identitet istaknutiji, veća 
Za Strajkera, što je neki identitet istaknutiji ili upadljiviji, verovatnije je da će biti prizvan u različitim kontekstima. Akter će tada verovatnije izvoditi uloge koje su konzistentne sa očekivanjima drugih u vezi sa tim identitetom, uključujući tu i svoj manjinski identitet (Stryker, 1980: 83; za raniju formulaciju koncepta istaknutosti identiteta u kontekstu porodičnih odnosa vidi i Stryker, 1968). Slično tome, akter će i razne društvene situacije češće interpretirati kao prilike za izvođenje i osnaživanje sopstvenog identiteta, odnosno osoba će tragati za situacijama u kojima je ovakvo izvođenje moguće (Stryker, 1980: 84).

Kada je reč o varijabli posvećenosti, ključan je lični i društveni odnos povezanosti aktera sa određenim identitetom. Naime, identiteti koje karakteriše snažna posvećenost predstavljaju identitete koji su najčešće "prizivani”, odnosno evocirani u društvenim situacijama (npr. akteri posvećeni odnosima zasnovanim na religiji imaju i snažne identitete religijskog karaktera). Varijabla posvećenosti identitetu je merljiva preko ekstenzivnosti (broja odnosa u koje ulazi akter) i intenzivnosti (dubine odnosa u koje ulazi akter) kao strukturnih dimenzija koji čine ovu varijablu (Stryker, 1980: 81).

Dakle, istaknutost identiteta i posvećenost identitetu za aktere u interakciji unutar društvene strukture predstavljaju ključne varijable za objašnjenje društvenog ponašanja čoveka. U tom smislu, formuliše se i svojevrsna hijerarhija identiteta ili, pojednostavljeno rečeno, da li smo u raznim svakodnevnim situacijama "prvo" i "pre svega" očevi, braća, muževi, crnci, katolici, Rusini, građani Srbije, sociolozi, levoruki itd. Ova hijerarhija identiteta je ključna za determinisanje ljudskog ponašanja zato što karakter i stepen određenog identiteta direktno utiče na izbore i akcije pojedinaca.

Piter Berk dinamici identiteta u kontekstu društvene interakcije pristupa na sličan način, odnosno on tvrdi da njegova teorija kontrole identiteta direktno "izrasta" iz Strajkerove teorije identiteta i strukturalnog simboličkog interakcionizma (Burke, 2007: 2202). Međutim, Berk dodatno unapređuje Strajkerove ideje, pre svega inkorporiranjem dimenzije emocija u analizu (kontrole) identiteta, ali i formulisanjem specifičnog kibernetskog modela ljudskog ponašanja. Prema teoriji kontrole identiteta, svaki identitet predstavlja kontrolni sistem (povratne sprege) sačinjen od četiri komponente:

je verovatnoća da će izvođenje uloge biti konzistentno sa očekivanjima od uloge pripisane tom identitetu; (7) što je identitet istaknutiji, veća je verovatnoća da će osoba neku datu situaciju percipirati kao priliku za izvođenje uloge koja je u vezi sa tim identitetom; (8) što je identitet istaknutiji, veća je verovatnoća da će pojedinac aktivno tragati za situacijama u kojima može izvoditi ulogu koja je u vezi sa tim identitetom; (9) što je veća posvećenost i veća istaknutost identiteta, kvalitet izvođenja uloge će imati veći uticaj na samopouzdanje; (10) što je veća posvećenost i veća istaknutost identiteta, veća je verovatnoća da će izvođenje uloge biti refleksija institucionalizovanih vrednosti i normi; (11) eksterni događaji koji raskidaju postojeće posvećenosti uvećavaju verovatnoću usvajanja novih identiteta; (12) što se više percipirane posledice projektovane promene identiteta odvijaju u pravcu osnaživanja vrednih posvećenosti, manji je otpor promeni (Stryker, 1980: 83-84). 
(1) standarda identiteta (skup značenja za neki identitet; šta znači biti nešto u određenoj situaciji, odnosno imati određenu društvenu ulogu, biti član neke društvene grupe itd.);

(2) percepcije značenja, kao inputa iz okruženja ili socijalne situacije $(\mathrm{u}$ situacijama koje su relevantne po naš identitet, najčešće u vidu povratnih informacija od strane drugih);

(3) komparacije značenja, kao procesa u kojem se input (percipirana značenja) upoređuje sa standardom identiteta;

(4) društvenog ponašanja, kao autputa ili ishoda procesa komparacije, koje je ispunjeno značenjem i usmereno ka okruženju (Burke, 1991: 837; vidi i Burke, 2007: 2203).

Navedeni sistem povratne sprege funkcioniše tako što modifikuje autput (društveno ponašanje) u skladu sa zahtevima društvene situacije. Osnovni zahtev društvene situacije predstavljaju pokušaji promene inputa (percepcije značenja), kako bi se značenja uskladila sa standardom identiteta (Burke, 1991: 837). Sistem kontrole identiteta na ovaj način deluje kao da ima nekakav "cilj", a to je usklađivanje inputa iz okruženja sa internim standardima identiteta. ${ }^{4}$

Berk identitet definiše kao skup značenja pripisanih sopstvu u nekoj društvenoj ulozi ili u situaciji koja definiše šta znači biti ono što neko jeste (Burke and Tully, 1977). Drugim rečima, standard identiteta se izražava u značenjima koje osobe pripisuju određenoj ulozi ili grupnom članstvu. Nečiji rodni identitet muškarca obično se izražava određenim stepenom maskuliniteta, (manjinski) identitet Rusina određenim (rusinskim) etnicitetom i/ili jezikom, identitet sociologa određenim stepenom znanja i veština iz sociologije itd. Na ovaj način, identiteti služe kao kontrolni sistemi koji kontrolišu percepcije (značenja relevantna za identitet) time što ih dovode u sklad sa značenjima po standardima identiteta. Ovaj proces, koji Berk naziva procesom kontrole identiteta, zapravo je proces aktivnog potvrđivanja ili verifikacije identiteta u interakciji. Dakle, ljudi delaju da bi potvrdili ili verifikovali svoje identitete, a u tom procesu izazivaju situacije $u$ kojima su relevantna (percipirana) značenja konzistentna sa njihovim ili većinskim standardom identiteta (Burke and Stets, 2009).

4 Da bi podrobnije objasnio ovaj model, Berk koristi analogiju sa termostatom: ovaj uređaj ima određeni standard (npr. 25 stepeni Celzijusa) i određeni input (temperaturu prostorije). Ukoliko je taj input 15 stepeni Celzijusa (dakle, 10 stepeni niže od standarda), komparacija između ove dve vrednosti će proizvesti autput koji uvećava temperaturu prostorije. Takav ishod traje sve dok ne postoji poklapanje između inputa (trenutne temperature prostorije) i standarda (25 stepeni Celzijusa) (Burke, 1991: 837). Drugim rečima, pojedinci u društvenoj interakciji percipiraju značenja koja su relevantna za sopstveni identitet kao kongruentna ili usklađena sa značenjima po standardu identiteta. U takvoj "neproblematičnoj” situaciji, diskrepancija između standarda i inputa je ravna nuli, te pojedinci ne menjaju svoje ponašanje. Međutim, ukoliko vrednost ove diskrepancije nije nula, individue će težiti promeni sopstvenih akcija, čime istovremeno menjaju i značenja u okvirima situacije, koja se zatim iznova percipiraju i upoređuju sa značenjima po standardu identiteta. 
Kada je reč o standardima identiteta, Berk diferencira i tri različite osnove identiteta: (1) identitete uloga (npr. šta znači biti u ulozi oca ili brata, sociologa ili kamiondžije), (2) socijalne identitete (npr. šta znači biti Rusin ili Amerikanac, muškarac ili žena) i (3) lične identitete (šta znači biti jedinstveno biološko biće). Tada je posebno važna konceptualizacija socijalnog identiteta (tj. identiteta utemeljenog na članstvu u nekoj grupi), za koji se tvrdi da obezbeđuje značenje sopstva koje je zajedničko za sve članove grupe (Stets and Burke, 2000). Na ovaj način, pojedinac se povezuje sa mnogim drugim i sebi sličnim pojedincima, a verifikacijom sopstvenog socijalnog identiteta kao člana grupe, on dobija priznanje, podršku i prihvatanje od drugih članova grupe. Drugim rečima, akterove veze sa drugim članovima grupe su iste ili slične kao i njihove međusobne veze, a verifikacija ovog identiteta istovremeno osnažuje razlike između članova grupe i grupnih autsajdera.

Berk analizira i fenomen promene identiteta, što su situacije u kojima se spomenute situacione diskrepancije rešavaju promenom standarda identiteta, a ne promenom percepcije značenja situacije. Tipični primeri ove vrste su iskustva ratnog zatvorenika, života u okvirima nekog kulta itd., u čemu je posebno važna varijabla društvene moći (tj. njenog odsustva kod aktera). Tipičan primer za ovo jesu deca, koja imaju veoma malo moći i samim tim su njihovi standardi identiteta pod velikim uticajem "moćnih" roditelja. Određena istraživanja ukazuju na to da se u specifičnim društvenim situacijama, npr. poput života sa cimerima u studentskom domu, neprekidno pregovara o identitetu osobe, što može odvesti u izmenjenu percepciju sopstva (McNulty and Swanm, 1994).

Inovacije takođe mogu predstavljati značajan uzrok promene identiteta, zato što pronalazak novih načina za ispunjavanje određene društvene uloge mogu promeniti očekivanja u vezi sa tom ulogom (npr. nagle tehnološke inovacije poput zamene pisaće mašine kompjuterom, što može imati posledice po standard identiteta računovođe ili sekretarice). Konačno, interesantno je i pitanje o međuodnosu različito utemeljenih identiteta i društvene strukture - npr. rodni identitet predstavlja identitet uloge, dok je identitet dominantne osobe lični identitet. S tim u vezi, Stets je istraživala odnos između ove dve vrste identiteta, kao i način na koji ovi identiteti zajednički ostvaruju kontrolu nad partnerom u kontekstu romantičnih veza (Stets, 1995).

Slično tome, Berk je istraživao rodne identitete i identitete supružnika kod nedavno venčanih parova u prvim godinama braka (Burke and Cast, 1997). U ovom istraživanju se ističe da rođenje deteta predstavlja tipičan izvor novih percepcija o sebi i drugome (supružniku), što rezultira u trajnom uticaju na prethodne percepcije u vezi sa rodom. Istraživanje je ukazalo na činjenicu da, kako muževi i žene preuzimaju uloge drugog, dolazi do promene njihovih 
standarda identiteta u pogledu roda, i to u pravcu međusobnog približavanja supružnika.

Drugim rečima, žene će se tada kretati u pravcu većeg maskuliniteta, a muškarci u pravcu feminiteta. Prema teoriji kontrole identiteta, ovo se dešava zbog potrebe za određenom "kompromisnom" pozicijom proizvodnje ponašanja koje može verifikovati oba identiteta kao međusobno usklađene i sa smislenim značenjima. Nivo do kojeg će se ovi standardi promeniti zavisiće i od drugih faktora, poput nivoa međusobne posvećenosti supružnika, njihovog odnosa moći i slično. Interesantno je i da postoje teorijski modeli koji konceptualizuju promenu identiteta kao rezultat određenog stresa, značajnog životnog događaja i slično (Kiecolt, 1994), a odnos između stresa i (promene) identiteta je problematizovao i sam Berk (Burke, 1991).

Koja je veza između teorije kontrole identiteta i (ličnih i društvenih) emocija? Osnovna pretpostavka teorije je u stavu da uspešna verifikacija identiteta generiše pozitivne emocije, dok odsustvo priznanja nečijeg identiteta izaziva negativne emocije poput besa, anksioznosti, depresije itd. (Stets and Tsushima, 2001). U sistemu povratne sprege koji postulira teorija kontrole identiteta, emocije signaliziraju stepen korespondencije između percepcija sopstva u situaciji i značenja standarda identiteta. Neprekidna korespondencija (ili odsustvo svake diskrepancije), proizvodi pozitivne emocije, što je slično Strajkerovim idejama o tome da adekvatno izvođenje uloge generiše pozitivne afekte (Stryker, 1980: 83). Međutim, Berk tvrdi da se negativne emocije pojavljuju čak i ako percepcije sopstva u situaciji prevaziđu značenja standarda identiteta, dok se Strajker prvobitno nije bavio ovim dimenzijama emocija (vidi Stets, 2006b: 209), odnosno tek je kasnije pisao o integrisanju emocija u teoriju identiteta (Stryker, 2004).

Prema teoriji kontrole identiteta, iskustvo negativnih emocija preti stabilnosti sistemu kontrole identiteta, zbog čega će pojedinci preduzimati različite strategije kako bi izašli iz negativnog stanja (npr. ponašaće se drugačije u datoj situaciji, razmišljaće o situaciji na drugačiji način itd.) (Burke, 1991). Manipulacija sopstvom koju tada preduzima akter obavlja se u cilju usklađivanja sopstva sa značenjima standarda identiteta, a vođeno je željom za pozitivnim emocijama. Emocionalne reakcije kao ishodi ili autputi usled diskrepancije između percepcije i standarda identiteta tiču se izgradnje skupa očekivanja koji akteri imaju u sebi, a mogu biti determinisani i učestalošću sa kojom se nečiji identitet dovodi u pitanje, kao i sa značajnošću izvora koji ga dovodi u pitanje (Stets, 2006b: 210). S tim u vezi, moguće je jasno razlikovati emocionalne ishode poput tuge, srama, besa i neprijateljstva (Stets, 2006b: 211). Svi ovi procesi su od izuzetnog značaja kada je reč o prikrivanju ili čak odustajanju od sopstvenog manjinskog identiteta (kao npr. od etničkog identiteta Roma, Jevreja, Rusina itd. pred izazovima diskriminacije). 
Konačno, Berk je tvrdio i da u slučajevima istaknutijih (salijentnijih) identiteta, kao i identiteta kojima je pojedinac posvećeniji, dolazi do pojave intenzivnijih emocija (Burke, 1991). Takođe, do intenzivnijih emocionalnih reakcija dolazi ukoliko bliska osoba ne verifikuje akterov identitet zato što je sa ovim osobama akter već izgradio skup zajednički verifikovanih očekivanja. Naime, prethodne interakcije su već održavale međusobne identitete, zbog čega izgrađena značenja formiraju dobro organizovan sistem. Zanimljivo je i da različiti tipovi identiteta proizvode različite emocionalne ishode: odsustvo verifikacije socijalnog identiteta vodi u stid, identiteta uloge u krivicu, a ličnog identiteta u tugu i depresiju (Stets, 2006b: 213).

Teoriju kontrole identiteta je podsticajno uporediti sa interakcionističkom teorijom emocija i društvene kontrole Suzan Šot (Shott 1979). Za nju, određene vrste emocija su toliko centralne za društvenu kontrolu da "društvo kakvo ga poznajemo ne bi moglo postojati bez njih [emocija]" (Shott 1979: 1318). Iako ona zauzima stav da je emocionalno iskustvo društveno konstruisano i da individue označavaju svoje emocije koristeći se oznakama stečenim u okvirima sopstvene kulture (Shott, 1979: 1320), zanimljivo je usredsrediti se na njenu (re) konceptualizaciju fenomena društvene kontrole. Prema Šot, individue u različite društvene situacije unose svoj opšti identitet, ali zatim u klasičnom interakcionističkom procesu preuzimanja uloge drugog (npr. Mead, 1934: 43-45) postaju fiziološki uzbuđeni. Emocije koje se pojavljuju u tom procesu Šot naziva "emocijama preuzimanja uloga" i tvrdi da one igraju ključnu ulogu za najveći deo društvene kontrole (a to je zapravo samokontrola) (Shott, 1979: 1323). Među emocijama preuzimanja uloga koje su usmerene ka samom sebi ("refleksivne emocije") nalaze se krivica, stid, posramljenost, ponos i taština, dok su emocije preuzimanja uloga usmerene ka drugima ("empatične emocije") sačinjene od one emocije koju oseća drugi (Shott, 1979: 1323).

Slično pojedinim pretpostavkama teorije kontrole identiteta, i Šot tvrdi da emocije kontrolišu ljudsko ponašanje tako što individue evaluiraju svoje uopštene i situacione identitete iz perspektive (uopštenog) drugog u datoj situaciji (Turner and Stets, 2005: 110). Na primer, krivica, stid i posramljenost proveravaju i kažnjavaju devijantna ponašanja (Shott, 1979: 1325), a ponos i taština su svojevrsne nagrade za propisano ili moralno ponašanje (Shott, 1979: 1326). Takođe, pozitivna osećanja empatije stvaraju snažne društvene veze, dok negativna osećanja empatije rezultiraju u altruističkom ponašanju.

Dodatna veza između njene teorije i teorije kontrole identiteta je stav da altruističko ponašanje predstavlja pokušaj popravke zamisli individue o samome sebi, odnosno o usklađivanju sopstvenog identiteta u kontekstu izazova iz okruženja (Shott, 1979: 1327). Prema Šot, upravo su emocije preuzimanja uloga u najvećoj meri "odgovorne" za to što je većina ljudskog ponašanja u skladu sa 
društvenim normama, čak i ako ne postoje evidentne eksterne nagrade ili kazne za to. Pošto je nemoguće ostvariti neprekidni nadzor i kažnjavanje nad ponašanjem članova društva, osnova društvene kontrole mora biti u samokontroli, pri čemu emocije preuzimanja uloge predstavljaju ključni mehanizam u tome (Shott, 1979: 1329).

S druge strane, teorija kontrole identiteta definiše identitete na osnovu kategorija i pozicija unutar društvene strukture, zbog čega i pripada tradiciji strukturalnog simboličkog interakcionizma (vidi Burke, 2004). Pozicija identiteta u nekom elementu društvene strukture, npr. u grupi ili mreži, neposredno ili posredno upravlja dostupnošću stvarnih i potencijalnih resursa. Na ovaj način, resursi koji su kontrolisani od strane identiteta zapravo su oni resursi koji održavaju društvenu strukturu time što održavaju grupe, uloge, pojedince i interakcije koji ih definišu. Drugim rečima, da bi se identitet razumeo u empirijskom smislu, neophodno je razumeti lokaciju navedenog identiteta u mreži društvene strukture, odnosno kakav je položaj određenih (manjinskih) identiteta (npr. žena, crnaca, katolika, homoseksualaca, Jevreja, Roma, Rusina itd.) u nekom društvenom sistemu. Svi ovi uvidi predstavljaju značajan konceptualni doprinos teorijama manjinskih identiteta u sociologiji.

Dakle, prema teoriji kontrole identiteta, kultura čini dostupnim različite kategorije i grupe koje čine društvenu strukturu, dok pojedinci (koji zauzimaju određene položaje unutar društvene strukture) zapravo pripisuju sebi i drugima određena značenja koja su povezana sa navedenim položajima u formi identiteta (Burke, 2004: 6). Ova značenja, konceptualizovana kao standardi identiteta, zatim definišu same identitete, ali i ciljeve koje neko ko se nalazi na određenom položaju stiče i perpetuira mehanizmima verifikacije identiteta. Na ovaj način, identitet je u inherentnoj vezi sa društvenom strukturom, a verifikacija identiteta postaje sredstvo putem kojeg se društvena struktura održava. Strukturni ili "sociološki" karakter teorije kontrole identiteta (kao, tradicionalno, socijalno psihološke kategorije) ogleda se u stavu da su identiteti u bliskoj vezi sa položajima u okvirima društvene strukture, pošto je navedeno da inputi dolaze iz akterovog socijalnog okruženja.

Zbog činjenice da ljudi zauzimaju različite uloge i položaje u mreži društvene strukture, kao i tvrdnje da su ove uloge i položaji ispunjeni značenjem u formi (manjinskog ili većinskog) identiteta - moguće je konceptualizovati i determinisanost društvene strukture čovekovim osećanjima. Na primer, može se pretpostaviti da će osobe sa zajedničkim afektivnim značenjima (usled zajedničkog manjinskog identiteta) biti sklonije stupanju u međusobne veze i motivisan(ij)e za održanje svog društvenog odnosa. To jest, pozitivne emocije će voditi u češće interakcije unutar odnosa, dok će negativne emocije imati suprotan efekat. Takođe, i izvođenje društvene uloge koje je u skladu sa kolektivnim ili većinskim 
očekivanjima od akterovog identiteta je proces koji generiše pozitivne emocije kod drugih (dopadanje, poštovanje itd.), kao i samopouzdanje kod aktera.

S tim u vezi, osećanja koja se proizvode tokom ovog društvenog odnosa utiču na posvećenost osobe tom odnosu, kao i sopstvenom (manjinskom) identitetu. Ovaj proces zatim doprinosi osnaživanju pripadnika manjinske zajednice, jačanju same manjinske zajednice, ali i generisanju šire društvene kohezije u datoj društvenoj strukturi. Iz tih razloga, svojevrsna "lekcija" koju za javne politike nude teorije kontrole afekta i kontrole identiteta je sledeća. Ukoliko želimo da očuvamo i osnažimo manjinske identitete, neophodno je obratiti pažnju (i) na varijable dominantnog značenja (ili standarda) identiteta u nekoj kulturi, na prakse jačanja grupne kohezije među manjinskim zajednicama, ali i na karakter društvenih emocija koje generiše verifikacija manjinskog identiteta u nekoj društvenoj interakciji ili društvenoj strukturi.

\section{LITERATURA}

Anderson, B. (1983/1991). Imagined Communities: Reflections on the Origin and Spread of Nationalism. Revised edition. London and New York: Verso.

Aronowitz, S. (1992). The Politics of Identity: Class, Culture, Social Movements. New York: Routledge.

Averett, C. and D. R. Heise (1988). Modified social identities: Amalgamations, attributions and emotions. In: L. Smith-Lovin and D. R. Heise (eds.) (1988). Analyzing Social Interaction:

Advances in Affect Control Theory (pp. 103-132). New York: Gordon and Breach Science Publishers.

Blumer, H. (1969). Symbolic Interactionism: Perspective and Method.Berkeley: University of California Press.

Burke, P. J. (1980). The self: Measurement requirements from an interactionist perspective. Social Psychology Quarterly 43 (1): 18-29.

Burke, P. J. (1991). Identity processes and social stress. American Sociological Review 56 (6): $836-849$.

Burke, P. J. (2004). Identities and social structure: The 2003 Cooley-Mead award address. Social Psychology Quarterly 67 (1): 5-15.

Burke, P. J. (2007). Identity control theory. In: G. Ritzer (ed.) (2007). The Blackwell Encyclopedia of Sociology (pp. 2202-2207). Oxford: Blackwell.

Burke, P. J. and A. D. Cast (1997). Stability and change in the gender identities of newly married couples. Social Psychology Quarterly 60 (4): 277-290.

Burke, P. J. and D. C. Reitzes (1981). The link between identity and role performance. Social Psychology Quarterly 44 (2): 83-92.

Burke, P. J. and J. E. Stets (2009). Identity Theory. Oxford and New York: Oxford University Press.

Burke, P. J. and J. C. Tully (1977). The measurement of role identity. Social Forces 55 (4): 881-897. 
Coupland, C. (2007). Identity: The management of meaning. In: G. Ritzer (ed.) (2007). The Blackwell Encyclopedia of Sociology (pp. 2210-2213). Malden: Blackwell Publishing.

Hobsbawm, E. and T. Ranger (eds.) (1983). The Invention of Tradition. Cambridge: Cambridge University Press.

Heise, D. R. (1965). Semantic differential profiles for 1,000 most frequent English words. Psychological Monographs 70 (8): 1-31.

Heise, D. R. (1970). The semantic differential and attitude research. In: G. Summers (ed.) (1970). Attitude Measurement (pp. 235-253). Chicago: Rand McNally.

Heise, D. R. (1977). Social action as the control of affect. Behavioral Science 22 (3): 163-177.

Heise, D. R. (1979). Understanding Events: Affect and the Construction of Social Action. New York: Cambridge University Press.

Heise, D. R. (2007). Expressive Order: Confirming Sentiments in Social Actions. New York: Springer.

Heise, D. R. (2010). Surveying Cultures: Discovering Shared Conceptions and Sentiments. New Jersey: John Wiley and Sons.

Howard, J. A. (2000). Social psychology of identities. Annual Review of Sociology 26: 367-393.

Jenkins, R. (2008). Social Identity. Third Edition. London and New York: Routledge.Kashima, Y., M. Foddy and M. J. Platow (eds.) (2002). Self and Identity: Personal, Social and Symbolic. Mahwah, New Jersey and London: Lawrence Erlbaum Associates Publishers.

Kemper, T. D. (2000). Emotions. In: E. F. Borgatta and R. J. V. Montgomery (eds.) (2000). Encyclopedia of Sociology, Vol. 2 (pp. 772-788). New York and Detroit: Macmillan Reference USA.

Kiecolt, K. J. (1994). Stress and the decision to change oneself: A theoretical model. Social Psychology Quarterly 57 (1): 49-63.

Kim, H. J. J. and R. B. Hupka (2002). Comparison of associative meaning of the concepts of anger, envy, fear, romantic jealousy, and sadness between English and Korean. CrossCultural Research 36 (3): 229-255.

Martin, R. and J. Barresi (eds.)(2003). Personal Identity. Oxford: Blackwell Publishing.

McNulty, S. E. and W. B. Swann (1994). Identity negotiation in roommate relationships: The self as architect and consequence of social reality. Journal of Personality and Social Psychology 67 (6): 1012-1023.

Mead, G. H. (1934). Mind, Self and Society, from the Standpoint of a Social Behaviorist. Edited by Charles W. Morris. Chicago: University of Chicago.

Osgood, C. E., G. J. Suci and P. H. Tannenbaum (1957). The Measurement of Meaning. Urbana and Chicago: University of Illinois Press.

Pullen, A. (2006). Managing Identity. New York: Palgrave Macmillan.

Robinson, D. T., L. Smith-Lovin and A. K. Wisecup (2006). Affect control theory. In: J. E. Stets and J. H. Turner (eds.) (2006). Handbook of the Sociology of Emotions (pp. 179-202). New York: Springer.

Romney, A. K, C. C. Moore and C. D. Rusch (1997). Cultural universals: Measuring the semantic structure of emotion terms in English and Japanese. Proceedings of the National Academy of Sciences of the United States of America 94 (10): 5489-5494.

Rusch, C. D. (2004). Cross-cultural variability of the semantic domain of emotion terms: An examination of English shame and embarrass with Japanese hazukashii. Cross-Cultural Research 38 (3): 236-248. 
Schneider, A. (1993). Sexual-erotic emotions in the U.S. in cross-cultural comparison. International Journal of Sociology and Social Policy 16 (9-10): 123-143.

Shott, S. (1979). Emotion and social life: A symbolic interactionist analysis. American Journal of Sociology 84 (6): 1317-1334.

Smith-Lovin, L. and D. Heise (eds.) (1988). Analyzing Social Interaction: Advances in Affect Control Theory. New York: Gordon and Breach Science Publishers.

Stets, J. E. (1995). Role identities and person identities: Gender identity, master identity, and controlling one's partner. Sociological Perspectives 38 (2): 129-150.

Stets, J. E. (2006a). Identity theory. In: P. J. Burke (ed.) (2006). Contemporary Social Psychological Theories (pp. 88-110). Stanford: Stanford University Press.

Stets, J. E. (2006b). Identity theory and emotions. In: J. E. Stets and J. H. Turner (eds.) (2006). Handbook of the Sociology of Emotions (pp. 203-223). New York: Springer.

Stets, J. E. and T. M. Tsushima (2001). Negative emotion and coping responses within identity control theory. Social Psychology Quarterly 64 (3): 283-295.

Stryker, S. (1968). Identity salience and role performance: The relevance of symbolic interaction theory for family research. Journal of Marriage and Family 30 (4): 558-564.

Stryker, S. (1980). Symbolic Interactionism: A Social Structural Version. Menlo Park: The Benjamin/Cummings Publishing Company.

Stryker, S. (2004). Integrating emotion into identity theory. In: J. H. Turner (ed.) (2004). Theory and Research on Human Emotions. Advances in Group Processes Vol. 21. (pp. 1-23).

Oxford: Elsevier.

Stryker, S. and P. J. Burke (2000). The past, present and future of an identity theory. Social Psychology Quarterly 63 (4): 284-297.

Škorić, M. i A. Kišjuhas (2015). Vodič kroz ideologije II. Novi Sad: Alternativna kulturna organizacija.

Turner, J. H. and J. E. Stets (2005). The Sociology of Emotions. Cambridge: Cambridge University Press. 
Aleksej Kišjuhas

\title{
MINORITY IDENTITIES: THE PERSPECTIVES OF AFFECT CONTROL AND IDENTITY CONTROL THEORIES
}

\begin{abstract}
SUMMARY
This paper presents and analyzes minority identities from the perspectives of affect control theory and identity control theory. These are the contemporary sociological theories of social interaction and social emotions, which refer to the phenomenon of social identity of an individual as well. The control mechanisms of affect and identity as generators of (minority) identities are analyzed, together with the analysis of social emotions and social meanings within the context of social interaction and social structure. In this manner, the affect control and identity control theories are presented as a valuable theoretical framework for an explanation of human social behavior with important consequences for the phenomenon of minority identity endurance and for the policies of preserving and nurturing minority identites.
\end{abstract}

Keywords: Identity, minority identities, affect control theory, identity control theory, meaning, social emotions. 